Cuadernos de Historia Contemporánea

ISSN: 0214-400X

http://dx.doi.org/10.5209/CHCO.54305

\title{
María Laffitte y Esperanza Rodríguez Cerdán: semblanzas para tejer la historia
}

Sergio Blanco Fajardo ${ }^{1}$

Barrera, Begoña: María Laffitte. Una biografía intelectual, Sevilla, Editorial Universidad de Sevilla, 2015.

Fernández Alonso, Rebeca: Esperanza Rodríguez Cerdán. La voz rebelde de una maestra sufragista, republicana y miliciana de la cultura, Sevilla, Editorial Benilde 2016.

En los primeros años de la Restauración, los ideólogos y políticos monárquicos trataron de apartar sistemáticamente los resquicios discursivos que permitieran reflexionar sobre la necesidad de cambiar los roles de género establecidos por la cultura patriarcal. La desigualdad entre hombres y mujeres estaba fuertemente establecida, a pesar de la existencia de una tradición republicana, internacionalista e igualitaria defendida en el Sexenio democrático por los núcleos femeninos que habían recogido el testigo de las socialistas utópicas de mediados del siglo XIX ${ }^{2}$. Por otra parte, las medidas culturales desarrolladas por krausistas e institucionistas desde posiciones políticas humanistas y reformistas, aunque supusieron una importante mejora de la condición femenina en los aspectos educativos y profesionales, resultaron contradictorias en lo que se refiere a la incardinación de las mujeres en la esfera pública. El poder se asociaba a la masculinidad, motivo por el que las mujeres no podían ni debían reclamar algo que no les pertenecía. Este hecho vino a reforzar, en diferentes planos, la tradicional división de esferas ${ }^{3}$. No obstante, en torno a este horizonte sociopolítico surgieron, ligadas a diversas culturas políticas y a presupuestos secularizadores, incluso confesionales, diferentes asociaciones y líderes femeninas cuyas reivindicaciones hablan de los cambios experimentados en las identidades individuales y colectivas en el cruce de los siglos XIX-XX'.

$1 \quad$ Universidad de Málaga (España)

E-mail: seblanfa@gmail.com

2 ESPIGADO TOCINO, Gloria: Mujeres "radicales": utópicas, republicanas e internacionalistas en España (1848-1874), Ayer n 60, 2005 (4), pp. 15-43.

3 FRAISSE, Geneviève: Los dos gobiernos: la familia y la ciudad. Madrid, Cátedra, 2003.

4 RAMOS, María Dolores (ed.): República y republicanas en España. Madrid, Marcial Pons, 2005. SANFELIU, Luz: Republicanas. Identidades de género en el blasquismo (1895-1910).València, Universitat de València, 2005. DEL MORAL, Marta: Acción colectiva femenina en Madrid (1909-1931). Santiago de Compostela, Universidad de Santiago, 2012. BLASCO, Inmaculada: Paradojas de la ortodoxia. Política de masas y militancia católica femenina en España (1919-1939). Zaragoza, Prensas Universitarias de Zaragoza, 2003. 
Así, en sentido paralelo al sustrato teórico y práctico del feminismo social durante aquellos años, el liberalismo comenzó a recoger algunas vindicaciones ligadas al terreno educativo y laboral, ensayó derechos y mejoras para las trabajadoras y se vio obligado a aceptar su protagonismo como agentes de ciudadanía. En el marco del reformismo ilustrado y humanista, Concepción Arenal (1820-1893) fue sin duda una figura pionera a la hora de demandar estos derechos y configurar un proyecto feminista que enmarcaba el protagonismo de las mujeres a través de la maternidad social y la labor de maestras, mecenas femeninas y benefactoras en el ámbito civil 5 . Discurso que se diferenciaba de los planteamientos del sufragismo anglosajón, estigmatizados en la prensa y en el terreno de las representaciones por amplios sectores de la opinión pública española, entre ellos, de manera muy enérgica, por los agentes eclesiásticos.

En el plano intelectual, Concepción Arenal rebatiría las teorías científicas que hacían de la mujer un ser inferior al hombre ${ }^{6}$, convergiendo sus ideas en este punto con las de María Laffitte, (1902-1986), de casada, condesa de Campo Alange ${ }^{7}$, objeto de estudio en la biografía de Begoña Barrera que aquí comentamos. Un estudio en el que, una vez más, la vuelta del sujeto individual al discurso histórico, y la mirada a lo particular y lo concreto ${ }^{8}$ se enriquece con el análisis del discurso, las posibilidades de actuación y las experiencias de una mujer que rompió barreras de género y clase para buscar espacios de libertad en un mundo hostil.

La vida de Lafitte pone de relieve la importancia de indagar en las condiciones político-culturales colectivas a la hora de explicar las acciones de los sujetos individuales, como señala María Sierra9 ${ }^{9}$ De ahí que en el libro que comentamos se ofrezca una clara visión de los límites políticos, culturales y morales establecidos por el franquismo, límites visibles no sólo en la trayectoria subjetiva de la biografiada y de varias generaciones de mujeres más, sino en la de quienes, sin distinción de sexo, sufrieron el rigor de la Dictadura.

Begoña Barrera ha construido una "biografía intelectual” de María Laffitte basándose en los propios postulados que emanan de sus obras. Se presenta la concepción de la ciencia, la idea de progreso y la preocupación por el problema social de la escritora como ejes de su pensamiento, y se resalta su inquietud por generar una serie de cambios que modernizaran a la sociedad española. Bajo la influencia, en gran medida, del jesuita Pierre Teilhard de Chardin, Laffitte optó por el evolucionismo tratando de conciliar ciencia y religión, y codeándose con los representantes de las vanguardias científicas europeas que aunaban ambos conceptos bajo el difuso manto del deísmo y de las corrientes espiritualistas ${ }^{10}$. Las líneas de pensamiento de María Laffitte sobre las mujeres pasaban por la necesidad de encontrar espacios comunes

LACALZADA DE MATEO, María José: La otra mitad del género humano. La panorámica vista por Concepción Arenal (1820-1893). Málaga, Universidad de Málaga, Atenea estudios sobre la Mujer, 1994.

6 LACALZADA DE MATEO, María José: "Las mujeres en la "cuestión social” de la Restauración: liberales y católicas (1875-1921)", Historia contemporánea, n 29, 2004, pp. 693-696,

7 LAFFITTE, María (Condesa de Campo Alange), La mujer en España. Cien años de su historia (1860-1960). Madrid, Aguilar, 1964.

8 HERNÁNDEZ SANDOICA, Elena: Tendencias historiográficas actuales. Escribir historia hoy. Madrid, Akal, 2004, pp. 401-406.

9 SIERRA, María: "Prólogo" a Begoña Barrera, María Laffitte. Una biografía intelectual. Sevilla, Editorial Universidad de Sevilla, 2015.

10 LALOUETTE, Jacqueline: La Libre Pensée en France, 1848-1940. Paris, Albin Michel, 1997, pp. $143-151$. 
que dignificara al sexo femenino a la luz de los preceptos emanados de la obra de Concepción Arenal.

Si la idea de progreso había sido una herramienta básica para resolver la contradicción surgida entre el componente epistemológico y el pragmatismo utilitarista, dicha herramienta debía usarse para conformar una solución positiva al deficiente estatus de las mujeres durante el franquismo. A juicio de Laffitte, el conflicto se iría disipando mediante la consolidación del concepto de "maternidad social", utilizado como estrategia para "imprimir en la cultura aquellos rasgos de feminidad que la preponderancia de lo "viril" había borrado o marginado" Laffitte esperaba que las mujeres interactuaran en la esfera pública y generaran una identidad colectiva emancipadora. Ahora bien, la creencia en el poder transformador de esta teoría, matizada y reformulada por el régimen franquista, deja entrever el carácter ingenuo y su personalidad, cierto "apoliticismo" de la biografiada. Quizás desde su evidente posición de clase y desde su experiencia subjetiva e intelectual, el control social y las violencias ejercidas sobre la mayoría de las mujeres españolas no resultaban tan evidentes para ella.

La diferencia entre "feminidad" y "feminismo" constituirá un importante apartado en el marco de las cuestiones a las que intentaba dar respuesta María Laffitte, como bien muestra Begoña Barrera. Al destacar el carácter esencial de la naturaleza femenina, basándolo en la maternidad, descartaba algunas de las ideas vigentes sobre el feminismo, pero nunca manifestó críticas hacia el movimiento de emancipación de las mujeres. Aunque las corrientes liberales y krausistas dejaron huella en su pensamiento, también la publicación de El Segundo Sexo, de Simone de Beauvoir (1908-1980), ${ }^{12}$ influyó notoriamente en ella, que, a pesar de sus diferencias ideológicas con la filósofa francesa, se inclinaría por aquel concepto de "otredad" que Beauvoir establecía en su libro, entendiendo que las mujeres eran construidas socioculturalmente, desde perspectivas patriarcales y androcéntricas. La lectura de la obra de Beauvoir significaría un antes y un después en la trayectoria de María Laffitte, tanto que en el encuentro que mantuvo con la feminista norteamericana Betty Friedan en España, dijo coincidir con las ideas de la autora de El segundo sexo y se pronunció a favor de "desencializar" el concepto "mujer". Redefinida su trayectoria intelectual, asimiló algunos planteamientos del feminismo de los años sesenta desde posiciones liberales e igualitarias. La adecuación a los nuevos paradigmas -que B. Barrera analiza con cuidado-, así como los cambios devenidos en la situación de las españolas en esos años, le exigieron una reestructuración intelectual. El profundo dinamismo de su pensamiento, su inquietud vital y su capacidad crítica le dieron alas para repensar la posición de las mujeres en la sociedad. Esta constante construcción epistemológica y su pragmatismo la empujaron a difundir la necesidad de trabajar por un modelo de feminidad diferente, definido por su carácter "moderno".

Begoña Barrera divide la biografía de María Laffitte en cinco capítulos. El primero, "Biografiar", muestra las pautas metodológicas e historiográficas establecidas en la investigación. En los dos siguientes aborda los mecanismos discursivos que permiten ver la evolución desde "lo femenino" a la concepción propiamente feminista de la biografiada. Por último, los capítulos: "Cuatro décadas de arte, intelectuali- 
dad y proyecto autobiográfico (1944-1983)" y "Un recorrido final: La emancipación ilustrada" arrojan interesantes reflexiones para entender el perfil intelectual y las experiencias de la escritora María Laffitte. El texto de Barrera contribuye así eficazmente a redefinir su figura y a contextualizar una etapa histórica en la que surgieron movilizaciones, reivindicaciones y un nuevo liderazgo femenino. En dicha etapa, las mujeres jugaron un importante papel como agentes sociales e históricos.

Hay que recordar, con todo, que el movimiento feminista presentaba aun en la segunda década del siglo XX las huellas de las corrientes de renovación pedagógica surgidas en el último tercio de la centuria anterior. La idea de una enseñanza activa basada en el laicismo, el racionalismo y, en cierta medida, la coeducación, estaba presente en los principios ideológicos de la Institución Libre de Enseñanza, la Escuela Nueva o la Escuela Moderna. Las doctrinas educativas renovadoras tuvieron un importante impacto, aun sectorial, en la sociedad española, y dinamizaron a un sector del funcionariado adscrito a la enseñanza, generando cambios no solo en las pautas pedagógicas y los programas escolares, sino también en las implicaciones sociales y políticas del profesorado.

Este despertar de una conciencia crítica y reivindicativa se refleja perfectamente en la biografía que Rebeca Fernández ha trazado sobre la maestra racionalista, feminista y socialista Esperanza Rodríguez Cerdán (1892-1984), una activa militante política, social y cultural durante el primer tercio del siglo XX, tras el comienzo de su periplo en la enseñanza en 1909. Imbuida de ideas progresistas, recorrió España debido a sus diversos destinos. Precisamente, en el desempeño de su trabajo pudo contemplar la pobreza y la miseria de numerosas zonas rurales y el atraso educativo y social de un país en declive. Esta situación le causó un gran impacto y fue el punto de partida de una concienciación que le llevaría a profesar un activismo y una militancia notables. Pronto se uniría a la Asociación de Profesores Regionalistas (1909) y a la Asociación General de Maestros (1912).

Desde muy joven la "cuestión femenina" fue para E. Cerdán un problema al que había que dar soluciones, dejando entrever así las primeras luces de su compromiso con el feminismo español. En 1919, Esperanza Rodríguez Cerdán sería elegida Delegada Provincial de Asturias de la Asociación de Nacional de Mujeres Españolas (ANME), una de las primeras entidades sufragistas de nuestro país ${ }^{13}$. Desde ese mismo instante, su activismo se incrementó, impartiendo conferencias y publicando artículos en defensa de los derechos de las mujeres. Es preciso recordar que durante la primera posguerra mundial el feminismo español ensayó nuevas estrategias y comenzó a reivindicar los derechos civiles y políticos femeninos desde la óptica de diferentes culturas políticas ${ }^{14}$. Ya los liberalismos radicales habían cuestionado el pasivo rol de las mujeres en la sociedad, bosquejándose la idea de disociar el constructo hombre/poder desde nuevas posiciones ideológicas, que desembocaron en una toma de conciencia sobre los derechos civiles, sociales y políticos femeninos y la reformulación de la ciudadanía de las mujeres. Así mismo, se prescindió del carácter esencialista del binomio esposa/madre. Este nuevo horizonte discursivo sacó a re-

13 FAGOAGA, Concha: La voz y el voto de las mujeres. El sufragio en España. 1877-1931. Barcelona, Icaria, 1985, pp. 127-139.

14 RAMOS, María Dolores; MORENO, Mónica (eds.): Mujeres y culturas políticas (Dossier), Pasado y Memoria. Revista de Historia Contemporánea $n^{\circ}$ 7, 2008, pp. 13-185; AGUADO, Ana (ed.): Culturas politicas y feminismos (Dossier), Historia Social n 67, 2010, pp. 69-171. 
lucir la capacidad de las mujeres para incidir en la esfera política y para reclamar el sufragio sin límites ni cortapisas.

Con la instauración de la Segunda República, el activismo feminista de Esperanza Rodríguez Cerdán se refuerza. Tras convertirse en 1933 en militante del PSOE, su compromiso político y social se radicaliza y se deja notar en sus publicaciones. En las revistas donde divulgaba sus trabajos de forma asidua denunciará a los "camaradas" que adoptaban posiciones más conservadoras. Otro hito importante será su elección, en 1933, como Alcaldesa-Presidente de Alameda del Valle, lugar en el que impartía clases, un rasgo identitario que no abandonaría jamás. Su incursión en el mundo de la política y su activismo transformaron no obstante sus pautas de conducta. Por ello, con un reforzado activismo político, presentó un manifiesto para defender la candidatura del Frente Popular, lo que le granjeó la animadversión, las presiones y coacciones de ciertos sectores conservadores decididos a cortar su cariz combativo. Esta experiencia muestra su clara integración en la esfera pública y su capacidad para incidir en el pensamiento de la gente, a favor o en contra de sus planteamientos, no solo mediante sus escritos, sino también gracias a su carisma y a su poder para provocar sentimientos encontrados, como ocurre en las situaciones de liderazgo. Características que dejan al descubierto su identidad política y permiten entrever que el modelo de la futura miliciana se fue conformando previamente en la etapa republicana.

Rebeca Fernández Alonso divide su libro en dos grandes capítulos: el primero versa sobre la vida de Esperanza Rodríguez Cerdán y el segundo abarca su militancia política y su producción literaria. Uno de los grandes aciertos de la obra reside en la presentación de una amplia documentación sobre los discursos y escritos de la biografiada, que constituyen una extraordinaria herramienta para acercarnos a su figura desde diferentes perspectivas. Este apartado es fundamental para comprender su compromiso, sus preocupaciones, su activismo y su militancia, y nos permite conocer a un personaje histórico notable pero olvidado, igual que ha sucedido, y sucede aún, con otras muchas mujeres españolas.

Por último, una precisión. La metodología utilizada en ambas biografías trasciende el ámbito de la historia de las mujeres para entrar en el campo de la historia sociocultural, la historia de las ideas y la historia de género. Las obras analizadas recogen el contexto sociopolítico en el que se movieron ambas mujeres, María Laffitte y Esperanza Rodríguez Cerdán, en el decurso histórico de sus experiencias vitales. Aunque formalmente existen ciertas disimilitudes en los dos textos, el interés por asociar subjetividades, identidades colectivas y escenarios es común y constante por parte de sus autoras. El aliciente para leer estas dos investigaciones no solo viene dado por la necesidad de rescatar del olvido o repensar la historia de dos mujeres que dejaron huella, sino que obedece al hecho, igualmente importante, de establecer ejemplos históricos que facilitan el abordaje de ciertas cuestiones: género, clase, identidades, prácticas de vida y culturas políticas, entre otras. De este modo, se interpretan, desde lo individual, lo cotidiano y lo colectivo, dos trayectorias de vida que ayudan a ensanchar el conocimiento de las realidades históricas y las especificidades de género, dejando al descubierto la pluralidad del movimiento feminista. Aunque el activismo de ambas biografiadas, como hemos apreciado, diverge en sus estrategias, no se puede decir lo mismo sobre la intensidad de su compromiso y su acción reformadora en un mundo que consideraban injusto e incompleto. 
En fin, los libros analizados nos acercan a la vida, las experiencias, el pensamiento y la obra de María Laffitte y Esperanza Rodríguez Cerdán, abren una ventana al mundo que conocieron, muestran su relación con él, los dispositivos que pusieron en marcha para transformarlo y los obstáculos que tuvieron que afrontar. Así se entiende con mayor profundidad la sinergia entre las experiencias individuales y colectivas, las representaciones simbólicas y materiales, y el pulso entre el poder y los mecanismos de resistencia a él que un puñado de mujeres establecieron en la sociedad española durante el siglo XX. Estos son, sin duda, algunos de los grandes aciertos de ambas biografías. 